\title{
Penile Leiomyosarcoma
}

National Cancer Institute

\section{Source}

National Cancer Institute. Penile Leiomyosarcoma. NCI Thesaurus. Code C162585.

A leiomyosarcoma that occurs in the penis. 